\title{
BMJ Open Harmful effects of early hyperoxaemia in patients admitted to general wards: an observational cohort study in South Korea
}

\author{
Jin Hee Jeong, ${ }^{1,2}$ Dong Hoon Kim,, ${ }^{1,2}$ Tae Yun Kim, ${ }^{1}$ Changwoo Kang, ${ }^{1,2}$ \\ Soo Hoon Lee, ${ }^{1}$ Sang Bong Lee, ${ }^{1}$ Seong Chun Kim, ${ }^{3}$ Yong Joo Park ${ }^{3}$
}

To cite: Jeong JH, Kim DH, Kim TY, et al. Harmful effects of early hyperoxaemia in patients admitted to general wards: an observational cohort study in South Korea. BMJ Open 2018;8:e21758. doi:10.1136/ bmjopen-2018-021758

- Prepublication history for this paper is available online. To view these files, please visit the journal online (http://dx.doi org/10.1136/bmjopen-2018021758).

Received 18 January 2018 Revised 2 October 2018 Accepted 4 October 2018

A Check for updates

(c) Author(s) (or their employer(s)) 2018. Re-use permitted under CC BY-NC. No commercial re-use. See rights and permissions. Published by BMJ.

1Department of Emergency Medicine, Gyeongsang National University School of Medicine and Gyeongsang National University Hospital, Jinju-si, Republic of Korea

${ }^{2}$ Gyeongsang Institute of Health Sciences, Gyeongsang National University School of Medicine, Jinju-si, Republic of Korea ${ }^{3}$ Department of Emergency Medicine, Gyeongsang National University School of Medicine and Gyeongsang National University Changwon Hospital, Changwon, Republic of Korea

Correspondence to

Dr Dong Hoon Kim;

kloud144@gmail.com

\section{ABSTRACT}

Objectives We evaluated the association between hyperoxaemia induced by a non-invasive oxygen supply for 3 days after emergency department (ED) arrival and the clinical outcomes at day 5 after ED arrival.

Design Observational cohort study.

Setting and patients Consecutive ED patients $\geq 16$ years of age with available arterial blood gas analysis results who were admitted to our hospital were enrolled from January 2010 to December 2016.

Interventions The highest $\left(\mathrm{PaO}_{2 \mathrm{MAX}}\right)$, average $\left(\mathrm{PaO}_{2 \mathrm{AVG}}\right)$ and median $\left(\mathrm{PaO}_{2 \mathrm{MED}}\right) \mathrm{PaO}_{2}$ (arterial oxygen pressure) values within 72 hours and the area under the curve divided by the time elapsed between ED admittance and the last $\mathrm{PaO}_{2}$ result $\left(\mathrm{AUC}_{72}\right)$ were used to assess hyperoxaemia. The AUC $_{72}$ values were calculated using the trapezoid rule. Outcomes The primary outcome was the 90-day inhospital mortality rate. The secondary outcomes were intensive care unit (ICU) transfer and respiratory failure at day 5 after ED arrival, as well as new-onset cardiovascular, coagulation, hepatic and renal dysfunction at day 5 after ED arrival.

Results Among the 10141 patients, the mortality rate was $5.8 \%$. The adjusted $\mathrm{ORs}$ of in-hospital mortality for $\mathrm{PaO}_{2 \text { MAX }}$ $\mathrm{PaO}_{2 \mathrm{AVG}}, \mathrm{PaO}_{2 \mathrm{MED}}$ and $\mathrm{AUC}_{72}$ were $0.79(95 \% \mathrm{Cl} 0.61$ to $1.02 ; p=0.0715), 0.92$ ( $95 \% \mathrm{Cl} 0.69$ to $1.24 ; p=0.5863$ ), $0.82(95 \% \mathrm{Cl} 0.61$ to $1.11 ; \mathrm{p}=0.2005)$ and $1.53(95 \%$ Cl 1.25 to $1.88 ; p<0.0001)$. All of the hyperoxaemia variables showed significant positive correlations with ICU transfer at day 5 after ED arrival $(p<0.05)$. UUC $_{72}$ was positively correlated with respiratory failure, as well as cardiovascular, hepatic and renal dysfunction $(p<0.05)$. $\mathrm{PaO}_{2 \mathrm{MAX}}$ was positively correlated with cardiovascular dysfunction. $\mathrm{PaO}_{2 \text { MAX }}$ and $\mathrm{AUC}_{72}$ were negatively correlated with coagulation dysfunction $(p<0.05)$.

Conclusions Hyperoxaemia during the first 3 days in patients outside the ICU is associated with in-hospital mortality and ICU transfer at day 5 after arrival at the ED.

\section{INTRODUCTION}

Supplemental oxygen is frequently required by hypoxaemic patients and is frequently given in various clinical settings. Physicians tend to believe that oxygen is safe and beneficial

\section{Strengths and limitations of this study}

- An observational cohort study of 10141 consecutive patients visiting the emergency department of a tertiary teaching hospital.

- The relationship between hyperoxaemia and clinical outcomes was analysed using various statistical measures: maximum, central tendency (average and median) and cumulative exposure in those patients who were admitted to a general ward.

- The impact of hyperoxaemia variables on clinical outcomes was adjusted for demographic, physiological and biochemical values.

- Severity adjustment with the National Early Warning Score rather than intensive care unit-based scores might lead to inaccurate results.

for both non-hypoxaemic and hyperoxaemic patients. ${ }^{1}$ However, hyperoxaemia is associated with poor clinical outcomes. ${ }^{2}$ Patients in intensive care units (ICUs) exhibiting high arterial oxygen $\mathrm{PaO}_{2}$ and a high fraction of inspired oxygen $\left(\mathrm{FiO}_{2}\right)$ experience more mortality than normoxaemic patients. ${ }^{3}$ Hyperoxaemia is associated with higher in-hospital mortality rates than normoxaemia in patients resuscitated from cardiac arrest. ${ }^{4-8}$ In addition, hyperoxaemia is associated with poor outcomes in patients with stroke, spontaneous subarachnoid haemorrhage and traumatic brain injury. ${ }^{7-11} \mathrm{~A}$ recent randomised controlled trial and a before-and-after study reported better outcomes in normoxaemic than hyperoxaemic ICU patients. ${ }^{12} 13$

Despite the evidence that hyperoxaemia is harmful, therapeutic strategies that prevent hyperoxaemia cannot be translated to all patients because the few relevant studies involved patients in ICUs or ventilator-assisted patients. ${ }^{391214}$ A certain proportion of emergency department (ED) patients require supplemental oxygen. Of these, some require 
mechanical ventilation and thus ICU admission. However, others receive supplemental oxygen non-invasively via a facial mask or nasal prong and are admitted to general wards. ${ }^{15}$ Only a few studies have explored the effects of hyperoxaemia on the clinical outcomes of ED patients. One study involved mechanically ventilated patients. ${ }^{14}$ Another study found that hyperoxaemia in ED patients induced by facial masks was harmful in those diagnosed with sepsis. ${ }^{16}$ However, that study involved a small number of patients, a limited disease spectrum and a single arterial blood gas (ABG) analysis result. No studies have evaluated the associations between hyperoxaemia and mortality in patients admitted to general wards. We hypothesised that hyperoxaemia induced by a non-invasive oxygen supply during the early treatment period would have adverse effects somewhat later in patients admitted to the general ward.

We evaluated the association between hyperoxaemia during the first 3 days after ED arrival and clinical outcomes day 5 after ED arrival.

\section{METHOD}

\section{Study design and setting}

We conducted a single-centre study at Gyeongsang National University Hospital, a tertiary teaching hospital located in the south central region of the Republic of Korea, from January 2010 to December 2016. This study was approved by our Institutional Review Board. All patients admitted to the ED are enrolled in the National Emergency Department Information System (NEDIS). The NEDIS was developed in 2003 to establish a national database of ED patients. ${ }^{17} 18$ The quality of the data was examined annually by the National Emergency Medical Centre, a government-funded, national ED control agency. In our ED, triage nurses and attending physicians entered patients' data into the NEDIS, including basic demographic and time values, physiological values at ED arrival, symptoms, diagnosis, treatment details (including drugs and procedures), outcomes and other information. The data were organised using the standard NEDIS registry format in the hospital electronic medical records (EMRs). The validity of all data was checked by function modules within the system before the data are saved.

\section{Participants}

All consecutive patients $\geq 16$ years of age with available ED ABG data who were admitted to the hospital with disease (not injury) during the study period were enrolled. We excluded patients with fewer than two $\mathrm{PaO}_{2}$ results within 72 hours of ED arrival. We also excluded patients with a maximum value of $\mathrm{PaO}_{2}$ within 72 hours $\left(\mathrm{PaO}_{2 \mathrm{MAX}}\right)$ of $<60 \mathrm{~mm} \mathrm{Hg}$ because we wished to compare hyperoxaemic and normoxaemic patients. Because we intended to assess delayed effects of hyperoxaemia, we also excluded patients who died prior to day 5 after ED arrival and who showed complications in the first 5 days (ICU transfer and respiratory failure, as well as new-onset cardiovascular, hepatic, renal and coagulation dysfunction).

The other exclusion criteria were transfer to other facilities after admission, discharge with no hope of recovery and left the hospital against medical advice. Patients with a hospital stay $>90$ days were excluded since their long stay may, potentially, be due to secondary problems. Moreover, we assumed that patients who were hospitalised $>90$ days would be free from the effects of early hyperoxaemia since there has been no study on how long the delayed effects of early hyperoxaemia last. Patients diagnosed with acute myocardial infarction were also excluded because supplemental oxygen is no longer recommended as a routine therapy in normoxaemic patients with acute myocardial infarction. ${ }^{19}$

\section{Data collection}

The data were extracted from the hospital EMR system. The demographic values recorded were age and sex. The physiological values were systolic blood pressure, heart rate, breathing rate, body temperature, arterial oxyhaemoglobin saturation and mental status (assessed as alert, verbal, pain and unresponsive). We also extracted data from the Prehospital Record and List of Therapeutic Management sections of the EMR to determine whether a given patient had received supplemental oxygen therapy before ED arrival. All patients were given oxygen during their ED stays. The National Early Warning Score (NEWS) was calculated in each patient to access the severity of illness. ${ }^{20}$ The $\mathrm{PaO}_{2}$ results determined by ABG analysis within 72 hours of ED arrival were collected. Time values between ED arrival and hospital discharge (dates of ED arrival, admission, ICU transfer, beginning of ventilator care, death and discharge) and final outcome (discharge, transfer, death or other) were also collected. Because we assessed complications of hyperoxaemia using the Sequential Organ Failure Assessment (SOFA) score components (cardiovascular, hepatic, renal and coagulation dysfunction), we evaluated the platelet count, and serum creatinine and bilirubin levels, at ED arrival and at day 5 after ED arrival, and determined whether a given patient received vasopressors. We also evaluated the use of mechanical ventilation therapy at day 5 after ED arrival to assess respiratory failure. Because the $\mathrm{PaO}_{2}: \mathrm{FIO}_{2}$ ratio could not be accurately calculated in the ED and general ward, respiratory failure was defined as the need for endotracheal intubation.

\section{Hyperoxaemic variables}

Among the hyperoxaemia metrics described by Helmerhorst $e$ al,$^{21}$ the highest $\left(\mathrm{PaO}_{2 \mathrm{MAX}}\right)$, average $\left(\mathrm{PaO}_{2 \mathrm{AVG}}\right)$ and median $\left(\mathrm{PaO}_{2 \mathrm{MED}}\right) \mathrm{PaO}_{2}$ values within 72 hours and the area under the curve divided by the time elapsed between $\mathrm{ED}$ arrival and the last $\mathrm{PaO}_{2}$ result $\left(\mathrm{AUC}_{72}\right)$ were used in this study. Using the $\mathrm{PaO}_{2 \mathrm{MED}}$ as the starting value $(\mathrm{t}=0$; ED arrival time) and the value at 72 hours $(t=72)$, the $\mathrm{AUC}_{79}$ was calculated using the trapezoid rule. Because no definition of hyperoxaemia has been established, we 
used the following upper quintile values: $137 \mathrm{~mm} \mathrm{Hg}$ for $\mathrm{PaO}_{2 \mathrm{MAX}}, 105 \mathrm{~mm} \mathrm{Hg}$ for $\mathrm{PaO}_{2 \mathrm{AVG}}, 103 \mathrm{~mm} \mathrm{Hg}$ for $\mathrm{PaO}_{2 \mathrm{MED}}$ and $174 \mathrm{~mm} \mathrm{Hg}$ for $\mathrm{AUC}_{72}$.

\section{Study outcome}

The primary outcome was the 90-day in-hospital mortality rate. The secondary outcomes were ICU transfer and respiratory failure at day 5 after ED arrival, and new-onset cardiovascular, coagulation, hepatic and renal dysfunction (SOFA subscore $\geq 2$ ) at day 5 after ED arrival.

\section{Data analysis}

Age was categorised as $16-39,40-79$ or $\geq 80$ years. All continuous variables showed a skewed distribution, and are presented as medians with IQRs. The Mann-Whitney $\mathrm{U}$ test was used to compare continuous variables, and Pearson's $\chi^{2}$ test for categorical variables.

Univariate logistic regression was performed using demographic and physiological data and the NEWS, laboratory values (platelet, creatinine and bilirubin levels and initial $\mathrm{PaO}_{2}$ ) and hyperoxaemia variables. Variables that were significantly $(\mathrm{p}<0.01)$ associated with the outcome in univariate analyses were used in the multivariate logistic regression model. The adjusted ORs of these variables were calculated for each hyperoxaemia value to assess their association with in-hospital mortality.

The secondary outcomes (ICU transfer, respiratory failure and new-onset cardiovascular, hepatic, renal and coagulation dysfunction at day 5) were subjected to the same analyses as the primary outcome. The $\mathrm{PaO}_{2 \mathrm{MAX}}$, $\mathrm{PaO}_{2 \mathrm{AVG}}, \mathrm{PaO}_{2 \mathrm{MED}}$ and $\mathrm{AUC}_{72}$ values were subjected to multivariate analyses.

All $\mathrm{p}$ values were two-sided, and a $\mathrm{p}$ value of $<0.05$ was considered indicative of statistical significance. Analyses were performed using MedCalc V.17 (MedCalc Software BVBA, Ostend, Belgium) and Stata V.13 (StataCorp, LP, College Station, Texas, USA).

\section{Patient and public involvement}

No patients were involved in the research question and outcome.

Arrived at the ED $(n=228,326)$

$$
\begin{aligned}
& \text { Enrolled }(n=32,821) \\
& \text { - Age } \geq 16 \text { years } \\
& \text { - Having arterial blood gas analysis results } \\
& \text { - Diseased, not injured } \\
& \text { - Admitted to the hospital }
\end{aligned}
$$
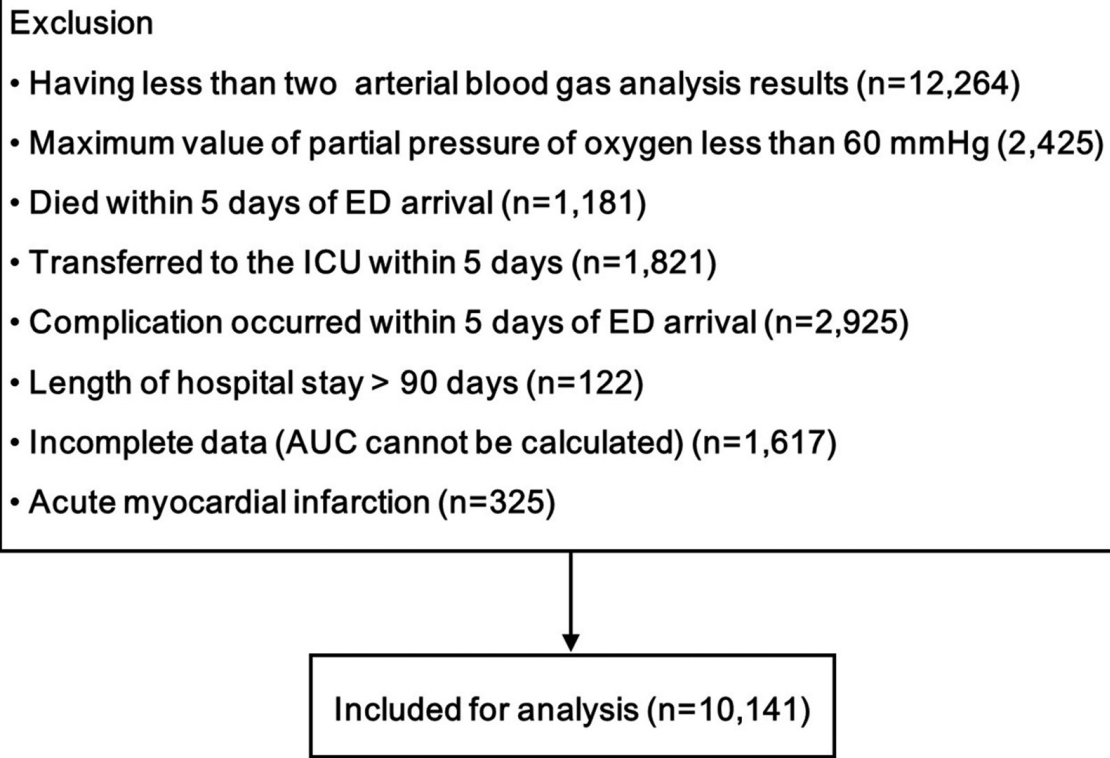

Figure 1 The study patients. AUC, area under the curve; ED, emergency department; ICU, intensive care unit. 


\begin{tabular}{|c|c|c|}
\hline Characteristics & Total & $\begin{array}{l}\text { Missing } \\
\text { data, n (\%) }\end{array}$ \\
\hline Number of patients & 10141 & \\
\hline Age, year & $69.0(57.0-78.0)$ & $0(0)$ \\
\hline \multicolumn{3}{|l|}{ Age category, n (\%) } \\
\hline $16-39$ & $786(7.8)$ & $0(0)$ \\
\hline $40-79$ & 7434 (73.3) & $0(0)$ \\
\hline$\geq 80$ & $1921(18.9)$ & $0(0)$ \\
\hline Male, n (\%) & $6040(59.6)$ & $0(0)$ \\
\hline \multicolumn{3}{|l|}{ Physiological variables } \\
\hline $\begin{array}{l}\text { Systolic blood pressure, } \\
\mathrm{mm} \mathrm{Hg}\end{array}$ & $130(110-150)$ & $0(0)$ \\
\hline Heart rate, beats/min & $90(78-108)$ & $0(0)$ \\
\hline Breath rate, breaths/min & $20(20-22)$ & $4(0.0)$ \\
\hline Body temperature, ${ }^{\circ} \mathrm{C}$ & $36.7(36.4-37.2)$ & $10(0.1)$ \\
\hline $\mathrm{SaO}_{2}, \%$ & $96(93-98)$ & $230(2.3)$ \\
\hline Consciousness (alert), n (\%) & 9076 (89.5) & $0(0)$ \\
\hline Supplemental oxygen, n (\%) & $4012(39.6)$ & $0(0)$ \\
\hline NEWS & $4(1-7)$ & $236(2.3)$ \\
\hline \multicolumn{3}{|l|}{ Initial laboratory results } \\
\hline Platelet, $\times 10^{3} / \mathrm{mm}^{3}$ & $220(162-287)$ & $56(0.6)$ \\
\hline Creatinine, mg/dL & $0.87(0.66-1.31)$ & $61(0.6)$ \\
\hline Bilirubin, mg/dL & $0.68(0.43-1.10)$ & $80(0.8)$ \\
\hline $\mathrm{PO}_{2}, \mathrm{~mm} \mathrm{Hg}$ & $76(59-96)$ & $371(3.7)$ \\
\hline \multicolumn{3}{|l|}{ Hyperoxaemia variables results } \\
\hline $\mathrm{PaO}_{2 \text { MAX }}$ & $99.0(83.0-126.0)$ & $0(0)$ \\
\hline $\mathrm{PaO}_{2 A V G}$ & $81.0(68.9-99.0)$ & $0(0)$ \\
\hline $\mathrm{PaO}_{2 M E D}$ & $80.0(67.5-97.5)$ & $0(0)$ \\
\hline $\mathrm{AUC}_{72}$ & $63.8(23.2-153.2)$ & $0(0)$ \\
\hline Mortality, n (\%) & $584(5.8)$ & $0(0)$ \\
\hline
\end{tabular}

$\mathrm{AUC}_{72}$, area under the curve divided by elapsed time between ED arrival and the last result of $\mathrm{PO}_{2}$ within 72 hours; NEWS, National Early Warning Score; $\mathrm{PaO}_{2 \mathrm{AVG}}$, average value of $\mathrm{PO}_{2}$ within 72 hours; $\mathrm{PaO}_{2 \mathrm{Max}}$, highest value of $\mathrm{PO}_{2}$ within 72 hours; $\mathrm{PaO}_{2 \mathrm{MED}}$, median value of $\mathrm{PO}_{2}$ within 72 hours; $\mathrm{PO}_{2}, \mathrm{PaO}_{2}$ of oxygen; $\mathrm{SaO}_{2}$, oxyhaemoglobin saturation.

Data are medians (IQR) unless otherwise stated.

No patients were involved in recruitment to this study.

The study results will not be disseminated to study participants.

This study is not a randomised controlled trial.

No patients were involved in the study design or conduct of the study.

\section{RESULTS}

\section{Baseline}

Of the 228326 patients who arrived at the ED during the study period, 32821 met the inclusion criteria. After applying the exclusion criteria, 10141 patients were eligible for analysis (figure 1). Men accounted for $59.6 \%$
Table 2 Univariate analysis of independent variables for 90 day in-hospital mortality

\begin{tabular}{|c|c|c|}
\hline Variable & OR & $P$ values \\
\hline Age 40-79year & $2.63(1.63-4.24)$ & 0.0001 \\
\hline Age $\geq 80$ year & $3.20(1.94-5.27)$ & $<0.0001$ \\
\hline Female & $0.54(0.45-0.65)$ & $<0.0001$ \\
\hline Systolic blood pressure & $0.99(0.99-0.99)$ & $<0.0001$ \\
\hline Heart rate & $1.01(1.01-1.02)$ & $<0.0001$ \\
\hline Breathing rate & $1.07(1.05-1.09)$ & $<0.0001$ \\
\hline Body temperature & $0.90(0.83-0.98)$ & 0.0143 \\
\hline $\mathrm{SaO}_{2}$ & $0.96(0.96-0.97)$ & $<0.0001$ \\
\hline Consciousness (non-alert) & $1.96(1.57-2.45)$ & $<0.0001$ \\
\hline Supplemental oxygen & $1.97(1.66-2.33)$ & $<0.0001$ \\
\hline NEWS & $1.14(1.11-1.16)$ & $<0.0001$ \\
\hline Platelet & $1.00(1.00-1.00)$ & 0.0659 \\
\hline Creatinine & $0.97(0.93-1.01)$ & 0.1875 \\
\hline Bilirubin & $1.15(1.12-1.17)$ & $<0.0001$ \\
\hline Initial $\mathrm{PO}_{2}$ & $0.99(0.99-1.00)$ & 0.0005 \\
\hline $\mathrm{PaO}_{2 \mathrm{MAX}}$ & $0.64(0.51-0.82)$ & 0.0003 \\
\hline $\mathrm{PaO}_{2 A V G}$ & $0.57(0.45-0.74)$ & $<0.0001$ \\
\hline $\mathrm{PaO}_{\text {2MED }}$ & $0.54(0.42-0.69)$ & $<0.0001$ \\
\hline $\mathrm{AUC}_{72}$ & $1.59(1.32-1.92)$ & $<0.0001$ \\
\hline
\end{tabular}

$\mathrm{AUC}_{72}$, area under the curve divided by elapsed time between ED arrival and the last result of $\mathrm{PO}_{2}$ within 72 hours; NEWS, National Early Warning Score; $\mathrm{PaO}_{2 \mathrm{AVG}}$, average value of $\mathrm{PO}_{2}$ within 72 hours; $\mathrm{PaO}_{2 \mathrm{Max}}$, highest value of $\mathrm{PO}_{2}$ within 72 hours; $\mathrm{PaO}_{2 M E D}$, median value of $\mathrm{PO}_{2}$ within 72 hours; $\mathrm{PO}_{2}, \mathrm{PaO}_{2}$ of oxygen; $\mathrm{SaO}_{2}$, oxyhaemoglobin saturation.

(6040) of patients, and the median age of the study population was 69 (IQR: 57-78) years old. The total number of ABG samples was 37908 and the mean number of ABG samples per patient was 3 (IQR 2-4) within 72 hours of $\mathrm{ED}$ arrival. The baseline characteristics of the patients are shown in table 1 .

\section{Primary outcome}

The results of univariate regression analyses are shown in table 2. Patient age, sex and all physiological variables such as systolic blood pressure, heart rate, breathing rate, body temperature, arterial oxyhaemoglobin saturation and mental status were significantly associated with 90-day in-hospital mortality. Regarding the initial values of the laboratory values, bilirubin and $\mathrm{PaO}_{2}$ were significantly associated with 90-day in-hospital mortality. The unadjusted ORs of $\mathrm{PaO}_{2 \mathrm{MAX}}, \mathrm{PaO}_{2 \mathrm{AVG}}, \mathrm{PaO}_{2 \mathrm{MED}}$ and $\mathrm{AUC}_{72}$ were 0.64 (95\% CI 0.51 to $0.82 ; \mathrm{p}=0.0003), 0.57$ (95\% CI 0.45 to $0.74 ; \mathrm{p}<0.0001), 0.54$ (95\% CI 0.42 to $0.69 ; \mathrm{p}<0.0001$ ) and 1.59 (95\% CI 1.32 to 1.92 ); $\mathrm{p}<0.0001$ ), respectively.

Because the values of the NEWS components (systolic blood pressure, heart rate, breath rate, body temperature, $\mathrm{SaO}_{2}$, supplemental oxygen and consciousness) had $\mathrm{p}$ values of $<0.01$ in univariate analyses, we subjected NEWS to multivariate regression analyses. The adjusted ORs of 
Table 3 Mortality and adjusted ORs for 90 day in-hospital mortality according to hyperoxaemia variables

\begin{tabular}{|c|c|c|c|c|}
\hline Variable & Patients, n (\%) & Deaths, n (\%) & OR $^{*}$ & P values \\
\hline $\mathrm{PaO}_{2 \mathrm{MAX}}$ & 10141 & & & \\
\hline Fourth quintile $(<137 \mathrm{~mm} \mathrm{Hg})$ & $8081(79.7)$ & $500(6.2)$ & 1 & \\
\hline \multicolumn{5}{|l|}{$\mathrm{PaO}_{2 \mathrm{AVG}}$} \\
\hline Fourth quintile $(<105 \mathrm{~mm} \mathrm{Hg})$ & 8140 (80.3) & $510(6.3)$ & & \\
\hline \multicolumn{5}{|l|}{$\mathrm{PaO}_{2 \mathrm{MED}}$} \\
\hline Fourth quintile $(<103 \mathrm{~mm} \mathrm{Hg})$ & $8111(80.0)$ & $513(6.3)$ & & \\
\hline Upper quintile ( $\geq 103 \mathrm{~mm} \mathrm{Hg}$ ) & $2030(20.0)$ & $71(3.5)$ & $0.82(0.61-1.11)$ & 0.2005 \\
\hline \multicolumn{5}{|l|}{$\mathrm{AUC}_{72}$} \\
\hline Fourth quintile $(<174 \mathrm{~mm} \mathrm{Hg})$ & $8124(80.1)$ & $422(5.2)$ & & \\
\hline
\end{tabular}

${ }^{*}$ Adjusted for age, sex, NEWS, initial bilirubin and initial $\mathrm{PO}_{2}$.

$\mathrm{PO}_{2}, \mathrm{PaO} 2$ of oxygen; $\mathrm{PaO}_{2 \mathrm{Max}}$, highest value of $\mathrm{PO}_{2}$ within 72 hours; $\mathrm{PaO}_{2 \mathrm{AVG}}$, average value of $\mathrm{PO}_{2}$ within 72 hours; $\mathrm{PaO}$ 2MED, median value of $\mathrm{PO}_{2}$ within 72 hours; $\mathrm{AUC}_{72}$, area under the curve divided by elapsed time between ED arrival and the last result of $\mathrm{PO}_{2}$ within 72 hours.

$\mathrm{PaO}_{2 \mathrm{MAX}}, \mathrm{PaO}_{2 \mathrm{AVG}}, \mathrm{PaO}_{2 \mathrm{MED}}$ and $\mathrm{AUC}_{72}$ were $0.79(95 \%$ CI 0.61 to $1.02 ; \mathrm{p}=0.0715), 0.92(95 \%$ CI 0.69 to 1.24 ; $\mathrm{p}=0.5863), 0.82(95 \%$ CI 0.61 to $1.11 ; \mathrm{p}=0.2005)$ and 1.53 (95\% CI 1.25 to $1.88 ; \mathrm{p}<0.0001)$, respectively (table 3 ).

\section{Secondary outcomes}

All of the hyperoxaemia variables were significantly positively correlated with ICU transfer at day 5after ED arrival (table 4). Among the hyperoxaemia variables, $\mathrm{AUC}_{72}$ had the highest OR for ICU transfer $(4.03 ; 95 \%$ CI 3.25 to $5.01 ; \mathrm{p}<0.0001)$. $\mathrm{AUC}_{72}$ was positively correlated with respiratory failure as well as cardiovascular, hepatic and renal dysfunction. $\mathrm{PaO}_{2 \mathrm{MAX}}$ was positively correlated with cardiovascular dysfunction. $\mathrm{PaO}_{2 \mathrm{MAx}}$ and $\mathrm{AUC}_{72}$ were negatively correlated with coagulation dysfunction $(0.64$; $95 \%$ CI 0.43 to $0.94 ; \mathrm{p}=0.022$ and $0.67 ; 95 \%$ CI 0.48 to $0.92 ; \mathrm{p}=0.015)$.

\section{DISCUSSION}

We assessed the association between hyperoxaemia during the first 72 hours and the outcomes at day 5 after ED arrival. In univariate analyses, all of the hyperoxaemia variables showed significant correlations with the 90 day in-hospital mortality rate (table 2). After adjustment, only $\mathrm{AUC}_{72}$ was significantly associated with the 90-day in-hospital mortality rate (table 3 ). $A U_{72}$ was significantly positively correlated with ICU transfer, respiratory failure, cardiovascular dysfunction, hepatic dysfunction and renal dysfunction. $\mathrm{PaO}_{2 \mathrm{MAX}}$ was significantly associated with ICU transfer and cardiovascular dysfunction. $\mathrm{PaO}_{2 \mathrm{MAX}}$ and $\mathrm{AUC}_{72}$ were negatively associated with coagulation dysfunction.

Only $\mathrm{AUC}_{72}$ was significantly associated with 90-day in-hospital mortality in this study; the one-time hyperoxaemia values $\left(\mathrm{PaO}_{2 \mathrm{MAX}}, \mathrm{PaO}_{2 \mathrm{AVG}}\right.$ and $\left.\mathrm{PaO}_{2 \mathrm{MED}}\right)$ were not. ${ }^{21} 22$ Because $\mathrm{AUC}_{72}$ is indicative of cumulative exposure to hyperoxaemia, it may reflect the degree of hyperoxaemia more accurately than the other variables.

The patients in this study were in a less-severe condition than those in previous studies. Our target population was patients who arrived at the ED but were not admitted to the ICU in the next 5 days. By contrast, previous studies involved only patients admitted to the ICU. ${ }^{3} 2122$ The median NEWS was 4 (IQR: 2-7). We considered that a NEWS $\geq 5$ reflected critical illness. ${ }^{20} 23$ We also used a non-invasive method of oxygen administration, unlike previous studies. Many patients in the ICU undergo mechanical ventilation. Mechanical ventilation may deliver a larger dose of oxygen in a more accurate manner. Patients who required higher oxygen levels, and those who were mechanically ventilated because of altered mentality or muscle weakness, were excluded from this study. We believe that this exclusion leads to a lower incidence of hyperoxaemia in this study than in previous studies. ${ }^{10-12}$ The single time exposure in non-critically ill patients under less severe hyperoxaemic conditions may not be as harmful and may therefore fail to show statistical significance in terms of the mortality rate. Instead, ICU transfer was used as an indicator of an increase in clinical severity in this study. Therefore, $\mathrm{AUC}_{72}$ is more suitable than the one-time hyperoxaemia values for assessing mortality and complications in these patients.

The significant association between $\mathrm{AUC}_{72}$ and cardiovascular and hepatic dysfunction is consistent with Girardis $e t a l,{ }^{12}$ which found that strict oxygen use reduces the rates of mortality, shock and liver failure compared with conventional oxygen use. Because that previous study was conducted in the ICU, this is the first report of $\mathrm{AUC}_{72}$ as an indicator of complications in non-ICU patients.

The $\mathrm{PaO}_{2 \mathrm{MAx}}$ and $\mathrm{AUC}_{72}$ values were associated with greater coagulation dysfunction. A previous study showed 
that coagulation dysfunction, as determined by fibrin deposition, occurs in patients with hyperoxaemia-induced acute lung injury, ${ }^{24}$ but has not been investigated extensively. Thus, further studies should evaluate the association between coagulation dysfunction and hyperoxaemia.

Hyperoxaemia toxicity is caused by the production of reactive oxygen species (ROS), pulmonary toxicity, haemodynamic alterations and neurological damage. ROS lead to lipid peroxidation, protein oxidation, DNA damage and direct pulmonary damage mediated by damage to the alveolar capillary barrier. Another pulmonary complication includes pulmonary gas exchange impairment by adsorption atelectasis. Haemodynamic alterations include reductions in cardiac output, coronary blood flow, myocardial $\mathrm{O}_{2}$ consumption and heart rate, as well as increased vascular resistance. Neurological damage is caused by excessive oxygen levels, which disrupt the protective mechanisms of the neural system under hyperbaric oxygen conditions. ${ }^{5724-27}$

However, it is unclear from which oxygen concentrations and after which exposure time toxicity may occur. The lung is first affected because of higher oxygen tension. ${ }^{28}$ In a study on baboons, alveolar septal injury occurred following exposure to $60 \% \mathrm{O}_{2}$ for 14 days. $^{29}$ In rabbits, lung injury developed following exposure to moderate hyperoxaemia at a large tidal volume for 2 hours. ${ }^{30}$ In humans, symptoms can occur at 10 hours after initial exposure to hyperoxaemia, ${ }^{31}$ although histological changes are apparent earlier. Helmerhorst $e t a \hat{l}^{2}$ reported that exposure to a high $\mathrm{FiO}_{2}$ for 15 min affected the systemic vascular resistance of patients who had undergone coronary artery bypass grafting surgery. Thus, physiological changes onset within minutes or hours after exposure to hyperoxaemia. We found that clinical outcomes (mortality and ICU transfer) were affected during the first 72 hours of exposure to hyperoxaemia. Therefore, physicians should be aware of the potential risks of early hyperoxaemia.

The present study had several limitations. First, we could not rule out selection bias, as the study population was limited to patients who visited our ED and underwent blood gas analysis. Second, because the NEWS was calculated using the initial values in the ED rather than ICU-based severity scores, the assessment of severity may have been inaccurate; if so, this would introduce bias into the regression model. Third, this study was conducted in a single centre; thus, a further multicentre randomised controlled study is warranted. Fourth, we excluded the patients with poor outcomes prior to day 5 after ED arrival because there is no compelling evidence about the onset time of clinical outcome following hyperoxaemia. A further prospective randomised study is needed with regard to these patients. Fifth, this was an observational cohort study; although statistical associations were evident, causation cannot be inferred. Some relevant factors may not have been measured.

Despite its limitations, this study was novel because we evaluated the association between hyperoxaemia 
and outcomes in non-critically ill patients presenting to the ED.

\section{CONCLUSION}

Hyperoxaemia during the first 3 days in ED patients was associated with higher in-hospital mortality and more common ICU transfer at day 5 after ED arrival.

Contributors $\mathrm{JHJ}$ : conceptualised and designed the study, analysed the data, drafted the initial manuscript, critically reviewed the manuscript, approved the final manuscript as submitted and agreed to be accountable for all aspects of the work. DHK: conceptualised and designed the study, coordinated and supervised data collection, critically reviewed the manuscript, approved the final manuscript as submitted, and agreed to be accountable for all aspects of the work. TYK, CK, SHL, SCK, YJP: interpreted data, critically reviewed the manuscript, approved the final manuscript as submitted and agreed to be accountable for all aspects of the work.

Funding The authors have not declared a specific grant for this research from any funding agency in the public, commercial or not-for-profit sectors.

Competing interests None declared.

Patient consent Not required.

Ethics approval Gyeongsang National University Hospital institutional review board.

Provenance and peer review Not commissioned; externally peer reviewed.

Data sharing statement Please contact author for data requests.

Open access This is an open access article distributed in accordance with the Creative Commons Attribution Non Commercial (CC BY-NC 4.0) license, which permits others to distribute, remix, adapt, build upon this work non-commercially, and license their derivative works on different terms, provided the original work is properly cited, appropriate credit is given, any changes made indicated, and the use is non-commercial. See: http://creativecommons.org/licenses/by-nc/4.0/.

\section{REFERENCES}

1. Suzuki S, Eastwood GM, Peck L, et al. Current oxygen management in mechanically ventilated patients: a prospective observational cohort study. J Crit Care 2013;28:647-54.

2. Helmerhorst HJ, Roos-Blom MJ, van Westerloo DJ, et al. Association between arterial hyperoxia and outcome in subsets of critical illness: a systematic review, meta-analysis, and meta-regression of cohort studies. Crit Care Med 2015;43:1508-19.

3. de Jonge E, Peelen L, Keijzers PJ, et al. Association between administered oxygen, arterial partial oxygen pressure and mortality in mechanically ventilated intensive care unit patients. Crit Care 2008;12:R156.

4. Elmer J, Scutella M, Pullalarevu R, et al. The association between hyperoxia and patient outcomes after cardiac arrest: analysis of a high-resolution database. Intensive Care Med 2015;41:49-57.

5. Llitjos JF, Mira JP, Duranteau J, et al. Hyperoxia toxicity after cardiac arrest: what is the evidence? Ann Intensive Care 2016;6:23.

6. Kilgannon JH, Jones AE, Shapiro NI, et al. Association between arterial hyperoxia following resuscitation from cardiac arrest and inhospital mortality. JAMA 2010;303:2165-71.

7. Damiani E, Adrario E, Girardis M, et al. Arterial hyperoxia and mortality in critically ill patients: a systematic review and metaanalysis. Crit Care 2014;18:711.

8. Wang $\mathrm{CH}$, Chang WT, Huang $\mathrm{CH}$, et al. The effect of hyperoxia on survival following adult cardiac arrest: a systematic review and metaanalysis of observational studies. Resuscitation 2014;85:1142-8.
9. Rincon F, Kang J, Maltenfort M, et al. Association between hyperoxia and mortality after stroke: a multicenter cohort study. Crit Care Med 2014;42:387-96.

10. Jeon SB, Choi HA, Badjatia N, et al. Hyperoxia may be related to delayed cerebral ischemia and poor outcome after subarachnoid haemorrhage. J Neurol Neurosurg Psychiatry 2014;85:1301-7.

11. Rincon F, Kang J, Vibbert M, et al. Significance of arterial hyperoxia and relationship with case fatality in traumatic brain injury: a multicentre cohort study. J Neurol Neurosurg Psychiatry 2014;85:799-805.

12. Girardis M, Busani S, Damiani E, et al. Effect of conservative vs conventional oxygen therapy on mortality among patients in an intensive care unit: the oxygen-icu randomized clinical trial. JAMA 2016;316:1583-9.

13. Helmerhorst HJ, Schultz MJ, van der Voort PH, et al. Effectiveness and clinical outcomes of a two-step implementation of conservative oxygenation targets in critically ill patients: a before and after trial. Crit Care Med 2016;44:554-63.

14. Page D, Ablordeppey E, Wessman BT, et al. Emergency department hyperoxia is associated with increased mortality in mechanically ventilated patients: a cohort study. Crit Care 2018;22:9.

15. O'Driscoll BR, Howard LS, Earis J, et al. BTS guideline for oxygen use in adults in healthcare and emergency settings. Thorax 2017;72(Suppl 1):ii1-ii90.

16. Stolmeijer R, ter Maaten JC, Zijlstra JG, et al. Oxygen therapy for sepsis patients in the emergency department: a little less? Eur $J$ Emerg Med 2014;21:233-5.

17. Cha WC, Shin SD, Cho JS, et al. The association between crowding and mortality in admitted pediatric patients from mixed adultpediatric emergency departments in Korea. Pediatr Emerg Care 2011;27:1136-41.

18. Yang HJ, Kim GW, Kim H, et al. Epidemiology and outcomes in outof-hospital cardiac arrest: a report from the NEDIS-based cardiac arrest registry in Korea. J Korean Med Sci 2015;30:95-103.

19. Nehme Z, Stub D, Bernard S, et al. Effect of supplemental oxygen exposure on myocardial injury in ST-elevation myocardial infarction. Heart 2016;102:444-51.

20. Alam N, Vegting IL, Houben E, et al. Exploring the performance of the National Early Warning Score (NEWS) in a European emergency department. Resuscitation 2015;90:111-5.

21. Helmerhorst HJ, Arts DL, Schultz MJ, et al. Metrics of arterial hyperoxia and associated outcomes in critical care. Crit Care Med 2017;45:187-95

22. Brenner M, Stein D, Hu P, et al. Association between early hyperoxia and worse outcomes after traumatic brain injury. Arch Surg 2012;147:1042-6.

23. Sbiti-Rohr D, Kutz A, Christ-Crain M, et al. The National Early Warning Score (NEWS) for outcome prediction in emergency department patients with community-acquired pneumonia: results from a 6-year prospective cohort study. BMJ Open 2016;6:e011021.

24. Mach WJ, Thimmesch AR, Pierce JT, et al. Consequences of hyperoxia and the toxicity of oxygen in the lung. Nurs Res Pract 2011;2011:260482.

25. Manning EP. Central nervous system oxygen toxicity and hyperbaric oxygen seizures. Aerosp Med Hum Perform 2016;87:477-86.

26. Kallet $\mathrm{RH}$, Matthay MA. Hyperoxic acute lung injury. Respir Care 2013;58:123-41.

27. Reinhart K, Bloos F, König F, et al. Reversible decrease of oxygen consumption by hyperoxia. Chest 1991;99:690-4.

28. Bitterman H. Bench-to-bedside review: oxygen as a drug. Crit Care 2009;13:205

29. Crapo JD, Hayatdavoudi G, Knapp MJ, et al. Progressive alveolar septal injury in primates exposed to $60 \%$ oxygen for 14 days. Am J Physiol 1994;267(6 Pt 1):L797-806.

30. Sinclair SE, Altemeier WA, Matute-Bello G, et al. Augmented lung injury due to interaction between hyperoxia and mechanical ventilation. Crit Care Med 2004;32:2496-501.

31. Chawla A, Lavania AK. Oxygen toxicity. Med J Armed Forces India 2001;57:131-3.

32. Helmerhorst HJF, de Wilde RBP, Lee DH, et al. Hemodynamic effects of short-term hyperoxia after coronary artery bypass grafting. Ann Intensive Care 2017;7:20. 